\title{
What Complementary and Alternative Medicine Practitioners Say About Health and Health Care
}

Bruce Barrett, $M D, P b D^{1}$

Lucille Marchand, $M D^{1}$

Jo Scheder, $P b D^{2}$

Diane Appelbaum, RN, C-NP, MS ${ }^{3}$

Mary Beth Plane, MSSW, PHD ${ }^{1}$

Joseph Blustein, MD, MPH

Rob Maberry, $B A^{1}$

Christina Capperino, $B S^{5}$

'Department of Family Medicine, University of Wisconsin-Madison, Madison, Wisc

${ }^{2}$ University of Wisconsin Madison, Madison, Wisc

${ }^{3}$ Emory University, Atlanta, Ga

${ }^{4}$ Department of Ophthalmology, University of Wisconsin-Madison, Wisc

${ }^{5}$ University of Wisconsin Medical Schoool, Madison, Wisc

Conflict of interest: none reported

\section{CORRESPONDING AUTHOR}

Bruce Barrett, MD, PhD

Department of Family Medicine

University of Wisconsin Medical School

777 South Mills

Madison, WI 53715

bbarrett@fammed.wisc.edu

\begin{abstract}
BACKGROUND We wanted to explore the beliefs and practices of complementary and alternative medicine (CAM) practitioners.
\end{abstract}

METHODS A representative sample of local CAM practitioners was selected for 32 face-to-face in-depth interviews. Interviews were taped, transcribed, and reviewed by all coauthors. Analysis and interpretation were reached by consensus, using an iterative process in multidisciplinary group meetings.

RESULTS The CAM practitioners interviewed stressed the holistic, empowering, and person-centered nature of CAM. They described themselves as healers, employing attentiveness, touch, and love to increase self-awareness and strengthen the healing process, usually in chronic illness, often with pain. They affirmed goodwill and respect toward conventional medicine, calling for greater integration of conventional and complementary health care; however, they identified the major differences of conventional medicine and several formidable barriers. They displayed concern about accessibility issues in health care and stressed that attitudes and beliefs were often larger impediments to integration than were economic or scientific considerations.

CONCLUSIONS In general, CAM practitioners want to work with physicians and other conventional health care workers in seeking a holistic, accessible, patientcentered, integrated health care system.

Ann Fam Med 2004;2:253-259. DOI: 10.1370/afm.81.

\section{INTRODUCTION}

The term complementary and alternative medicine $e^{1}$ (CAM) is used to encompass a broad range of healing modalities. In 1993, Eisenberg and colleagues ${ }^{2}$ loosely equated CAM with "unconventional medicine," defining it as "medical interventions not taught widely at US medical schools or generally available at US hospitals."

Ernst et al provide the following definition: "diagnosis, treatment and/or prevention which complements mainstream medicine by contributing to a common whole, by satisfying a demand not met by orthodoxy or by diversifying the conceptual frameworks of medicine." ${ }^{13,4}$ The 1993 article by Eisenberg et $\mathrm{al}^{2}$ highlighted evidence of CAM's emerging importance, reporting a $34 \%$ prevalence-of-use rate, 425 million yearly visits to CAM practitioners (compared with 388 million visits to primary care physicians), and an estimated total expenditure of $\$ 13.7$ billion. A follow-up study published in 1998 reported significant increases in CAM use, with prevalence of use up to $42 \%$, visits at 629 million, and expenditures "conservatively estimated" at $\$ 27.0$ billion. ${ }^{5}$ For comparison, that same year Americans made 386 million visits to primary care physicians and paid out-of-pocket costs of $\$ 9.1$ billion for hospitalizations and $\$ 29.3$ billion for all physician services. ${ }^{5-10}$ 
Although these statistics are sufficient to bring attention to CAM healing methods, they provide little in the way of in-depth understanding. We believe that this largely unexplored area can be better understood through the use of qualitative methods aimed at knowledge, attitude, and practices of CAM healers and their patients. Whereas the literature describing patients' use of CAM and conventional medicine's attitudes toward CAM has been growing in depth and breadth, ${ }^{11-15}$ there is very little published research targeting CAM practitioners themselves. Interested in understanding the boundaries and barriers between conventional health care and CAM, we chose to design a study that would investigate the conceptual frameworks of CAM practitioners. We were particularly interested in exploring CAM practitioners' ideas regarding the possibilities of integrating conventional, complementary, and alternative perspectives, practices, and systems.

\section{METHODS}

This exploratory, descriptive, qualitative study used methods aimed at investigating the attitudes, beliefs, and insights of CAM practitioners. Wishing to explore this arena without the limitations inherent in a formal survey or experimental hypothesis testing, we chose to use the qualitative method of in-person, long interviews as our primary research strategy. ${ }^{11,16-23} \mathrm{We}$ did not come to this design from a blank slate, however. Instead, we were familiar with a wide variety of research, experience, and conceptual frameworks. Our team consisted of an anthropologist-family physician (BB), a family physician-qualitative researcher (LM), a biocultural anthropologist (JS), a nurse practitioner with strong interest in CAM (DA), a social welfare researcher $(\mathrm{MBP})$, a physician epidemiologist (JB), a medical student (CC), and the study coordinator (RM). Four of us had already published a study involving both practitioners and users of CAM, in which we proposed the HEAL framework, an acronym arising from the 4 emerging themes: holism, empowerment, access, and legitimacy. ${ }^{13}$ This work, and our multidisciplinary training, influenced the design and conduct of our study. Although we all work within a conventional universitybased system, we are likely more CAM-oriented than most of our conventional health care colleagues.

For the current project, we were specifically interested in (1) what CAM practitioners did in their practices, (2) their philosophy of health and healing, and (3) their beliefs and behaviors regarding other health practitioners, both conventional and alternative. A prominent underlying motivation was to explore the possibilities of integrating conventional and complementary health care ${ }^{24}$ and to open communication

\section{Table 1. Questions Asked in All Interviews}

What are the most common therapies you practice or prescribe? What are the most common presenting problems in your practice? Do you use CAM therapies exclusive of-or along with-conventional (allopathic) medicine?

To what extent do you think the client's own beliefs help in healing? How do you use these beliefs?

How much attention do you give to family or social support networks of your client?

How do you use these networks in helping your client?

Would you like to work more closely with any other type of health practitioner? If so, what kind(s)?

Under what circumstances do you consult with or refer to other practitioners?

How is your practice similar to conventional (allopathic) medicine?

How is your practice different from conventional medicine?

What are the barriers you see existing between conventional and complementary medicine?

How do you think alternative and conventional practitioners can work together better?

What is your vision of the optimal health care system?

channels between CAM and conventional health care. With these objectives in mind, over several weeks and with substantial pretesting, we created a semistructured interview guide based on open-ended questions designed to elicit honest and thoughtful discussion. The standardized questions depicted in Table 1 were supplemented by additional questions (probes) deemed appropriate by the interviewer, either for clarification, or to stimulate further discussion on a topic of interest.

Our sampling universe consisted of all CAM practitioners working in Madison, Wisc. In principle, we followed the definitions of CAM noted above. ${ }^{2-4}$ In practice, we sought people practicing the modalities noted in Table 2. We chose to exclude chiropractic because in Wisconsin chiropractors are widely available, with reimbursement mandated by law, and thus are considered to be conventional by much of the populace. (We did interview 1 person who described herself as a holistic chiropractor.)

We began seeking out Madison-area CAM practitioners in 1998, in preparation for our first study, ${ }^{13}$ so we had a preexisting listing of more than 100 practitioners. We updated this list in the spring of 2000, using the telephone book, notices in pharmacies and health food stores, telephone calls, and interviews with knowledgeable informants. Once we believed our list was sufficiently comprehensive (250 practitioners in 28 modalities), we stratified by CAM modality, then randomly selected within category. We wanted to avoid too many interviews per modality (more than 80 of the 250 names were massage therapists), so limited the maximum number of respondents to 4 per modality. We aimed for at least 1 interview per modality, with small and medium-size categories represented by 


\section{Table 2. Characteristics of Study Practitioners}

\begin{tabular}{|c|c|c|c|}
\hline Characteristics & Number & Characteristics & Number \\
\hline Sex & & Modalities & \\
\hline Male & 11 & Acupuncture & 4 \\
\hline Female & 21 & Aromatherapy & 1 \\
\hline \multirow{3}{*}{$\begin{array}{l}\text { Age, years, } \\
\text { mean (range) }\end{array}$} & \multirow{3}{*}{$\begin{array}{l}47.6 \\
(31-62)\end{array}$} & Astrology & 2 \\
\hline & & Chinese medicine & 3 \\
\hline & & Chiropractic, holistic & 1 \\
\hline \multicolumn{2}{|l|}{ Ethnicity } & Colonics & 1 \\
\hline White & 25 & Energy healing & 1 \\
\hline Jewish & 2 & Feldenkrais & 2 \\
\hline Asian & 2 & Flower remedies & 1 \\
\hline \multirow[t]{2}{*}{ Unknown } & \multirow[t]{2}{*}{3} & Herbalism & 2 \\
\hline & & Homeopathy & 2 \\
\hline \multicolumn{2}{|l|}{$\begin{array}{l}\text { Household income } \\
\text { (thousands per year) }\end{array}$} & Massage & 3 \\
\hline$\$ 10$ to $<\$ 20$ & 3 & Medical intuition & 1 \\
\hline$\$ 20$ to $<\$ 30$ & 4 & Naturopathy & 1 \\
\hline$\$ 30$ to $<\$ 50$ & 11 & Rolfing & 1 \\
\hline \multirow{2}{*}{$\begin{array}{l}\$ 50 \text { to }<\$ 75 \\
>\$ 75\end{array}$} & 3 & Shmanism & 1 \\
\hline & 4 & T'ai Chi & 1 \\
\hline \multirow{3}{*}{ Unknown } & \multirow{3}{*}{7} & Touch & 1 \\
\hline & & Trager & 1 \\
\hline & & Yoga & 2 \\
\hline
\end{tabular}

2 or 3 interviews, and large categories getting 3 or 4 interviews. In all, a total of 58 names representing 28 modalities were selected. By definition, we chose to include only those practitioners seeing 5 or more clients per week.

To make contact, we telephoned the practitioners and requested an interview. For those eligible and willing, interviews were conducted in person, following informed consent procedures approved by our Institutional Review Board. Each team member (coauthor) conducted at least 2 interviews. Interviews were usually carried out in the respondent's office, studio, or home. All interviews were audiotaped, then transcribed, with identifiers removed. Transcriptions were reviewed individually by all team members, using standard qualitative methods, loosely based on an editing analysis style. ${ }^{17-19,25-28}$ All team members reviewed transcripts before monthly review meetings, using worksheets asking for items (ideas, words, quotes), page number(s),

\section{Table 3. Practice Characteristics Study Participants}

\begin{tabular}{lccccc}
\hline Practice Characteristics & Responses* $^{*}$ & Range & Mean & Median & SD \\
\hline Years practicing $^{\dagger}$ & 25 & $1-25$ & 9 & 9 & 9.2 \\
Hours per session $^{\dagger}$ & 24 & $0.08-2.0$ & 1.1 & 1 & .04 \\
Clients per week $^{\dagger}$ & 20 & $2-60$ & 20.1 & 20 & 14 \\
${\text { Payment rate per visit }(\$)^{\dagger}}^{+}$ & 24 & $0-188$ & 75 & 70 & 40 \\
\hline * Several respondents could not or would not estimate these parameters for us. & \\
† Excludes 2 respondents who taught classes.
\end{tabular}

and emerging themes (conceptual entities tying items together). Items noted by individual reviewers were discussed and noted on group worksheets, which consisted of newsprint-sized sheets taped to walls in full view of all reviewers. Items were also organized into topics and themes in these group meetings, by consensus, after thorough discussion. Additionally, we used the N-Vivo qualitative research software package $^{29}$ for data management and to assist with hierarchical modeling of items and themes

\section{RESULTS}

Of the 58 names selected for interview, 32 were actually interviewed, all in person. We were unable to reach 9 of the selected practitioners, despite multiple calls. Five had moved away from our study area, 4 were no longer practicing CAM, and 4 had changed CAM modality. Three saw fewer than 5 clients per week. One declined for health reasons. Table 2 and Table 3 display descriptive information regarding the CAM practitioners we interviewed. Interviews lasted 45 to 90 minutes. Transcripts ranged from 3,300 to 10,000 words. A total of 20 multidisciplinary review meetings were held from December 2, 1999, to September 18, 2001. Sixteen meetings were dedicated to transcript analysis. Whereas the earlier interviews yielded many important new findings, later interviews resulted in diminishing returns, with fewer and fewer new ideas noted. By the time we reached 32 interviews, we had reached data saturation.

Analysis and interpretation of the 32 interviews provided a conceptual framework through which to understand CAM, both as an entity unto itself, and in relation to conventional medicine. Table 4 provides a list of the issues that, according to our respondents, differentiate CAM from conventional therapy. A list of potential barriers to integration is also provided. The issues depicted in this table arose repeatedly during the interviews and were described as differences and potential roadblocks to the integration of CAM and conventional medicine. Although conventional medicine was portrayed as more scientific and thus more legitimate, CAM therapies were described as more intuitive, individualized, empowering, 


\section{Table 4. Differences Between CAM and Conventional Medicine, and Barriers to Integration}

\begin{tabular}{ll}
\hline Conventional Medicine & $\begin{array}{l}\text { Complementary and } \\
\text { Alternative Medicine }\end{array}$ \\
\hline $\begin{array}{l}\text { Differences } \\
\text { More reductionistic }\end{array}$ & More holistic \\
More deductive & More empowering \\
More generalizable & More inductive \\
More scientific & More individualistic \\
Less time with patient & More intuitive \\
Barriers to Integration & More time with client \\
Arrogance & \\
Belief of ineffectiveness of CAM & Lack of communication \\
Competition & Lack of legal recognition \\
Costs and cost effectiveness & Lack of training \\
Distrust & Philosophical differences \\
Fear of liability & Political pressures \\
Ignorance & Prejudice \\
Momentum (habits and tradition) & Profit motive \\
Lack of availability & Territorialism \\
& \\
\hline
\end{tabular}

and holistic. Conventional medicine was said to be more physically and financially accessible (at least to those with health insurance). Nevertheless, CAM was described as more culturally or psychologically accessible, especially to those with alternative, New Age or culturally creative ${ }^{30,31}$ philosophical orientations. ${ }^{32}$ Even so, our informants made clear that the characteristics that define CAM and distinguish it from conventional medicine are complex sets of overlapping attributes rather than discrete entities.

Generalizations, while mostly true, imperfectly capture the diversity of both CAM and conventional medicine. CAM practitioners described the many reasons why people came to see them, emphasizing the chronic rather than acute nature of most health problems. They also pointed out that most people had tried conventional medicine for some time before coming to see them. As one practitioner put it, "I mean, pretty typically, people come to see me because they're not getting any help elsewhere." Back pain, joint pain, depression, diabetes, cancer, and other illnesses familiar to primary care clinicians were identified. Although the illness spectrum was familiar, CAM practitioner attitudes toward these illnesses differed from the attitudes of our conventional colleagues. Underlying causes, identified as imbalances in energy or spirit, were highlighted, as shown in the following comments: (1) "I think a lot of chronic issues in the muscular-skeletal system are really caused by emotional issues-energy that is not moving ... tension is energy that is not in motion." (2) "I think of symptoms as secondary things that show up because of the fact that there's something ... something else that's causing this imbalance." (3) "When we don't deal with issues on the spiritual, mental and emotional, they will then break through into the physical plane." (4) "If people can really get down to the original cause of their distress, and, you know, what's really creating a somaticizing of blocked energy ...." While pain was the primary reason for seeking CAM, practitioners did not describe pain as an entity to be combated. One respondent said, "Pain is our greatest teacher and guide." Another asserted that, "Pain is not a bad thing. It keeps you in line."

CAM practitioners represent themselves as being more in congruence with patients in terms of health belief, world view, and style than is true with conventional medicine. They see themselves as educators and coaches as well as healers. One respondent said, "I do a lot of preventive teaching. I love to teach." Another put it this way, "I pay attention to what my intuition says. Sometimes it seems to me that what I'm really doing is teaching people to listen to themselves in a really profound, empowering way." A third said, "We see our work as being fundamentally about learning and about education, less about fixing a person's problem."

CAM practitioners describe themselves as holistic and argue that health and healing are related to holism. One respondent said, "I think we treat the whole person, the whole body. I think medicine is about whole ... it's human medicine, it's the whole body-mind and body — not just the symptom." Another said, "I guess I equate healing and integration in a lot of ways because I know that the root word of the word 'heal' is connected etymologically to the word 'whole.' In my belief system 'whole-making' is 'healing."' According to our respondents, CAM is effective partially because practitioners take the time to get to know their clients. The timeconstrained, hurried nature of conventional medical visits was noted as a major barrier to good health care.

CAM practitioners say that they work to empower patients and try to get people to take responsibility for their own health. As one respondent put it, "It isn't my job to heal them. It's their job to heal themselves." Another said, "Part of what my work with them is for them to take responsibility." The quest for health was often related to the ability - and willingness - to change beliefs as well as behaviors. A respondent said, "I do feel that beliefs are really, fundamentally important. If we don't change beliefs, we can't change behaviors." In response to our last question "Do you have any final thoughts?" one respondent said, "Empower the people to empower themselves."

CAM practitioners display and encourage positive attitudes. They place high value on world view, belief, 
and healthy living. As one respondent put it, "A human person is one who is inherently intelligent and capable and flexible and strong and honest and loving and lovable.... I don't see them as a problem. I see them as inherently healthy. And I look to see what's getting in the way of them living their health." Another said, "If you're constantly focusing on negative feelings, and constantly seeing the world with a half-empty cup, ... I can't help but think your life is not going to be as healthy as someone who does see the world with a cup half full."

CAM practitioners assert the value of touch as therapy. As one said, "Touch is so powerful ... I don't think there are definite answers as to why it works." Another said, "I believe that touch is the key. It's not so much in massage, I really believe it's the people's need for touch, which is why people come for massage.... We're just so deprived, I think, of general, warm touch." CAM practitioners stress the healing power of love.

One said, "We can't do a damn thing for anybody unless we love them." Another concluded, "It's quite frankly ridiculous to be spending millions and millions and millions of dollars on high tech, when what a person really wants is love."

CAM practitioners described their visions of an optimal health care system. They argued for holistic, empowering, and accessible health care. They voiced the need for an integrated health care system, in the sense that both CAM and conventional options would be available, and for legitimacy, portrayed as a combination of scientific backing, institutional integrity, and societal respect. Many also stressed the need for rational, national, universal health care. ${ }^{33}$ One said, "Well, everyone should have health care. Period. That's number one. It's shocking in this country that we don't." CAM practitioners were critical of the increasingly privatized, for-profit health care institutions, pointing out inequity, inefficiency, ineffectiveness, and iatrogenic causes of illness as major unresolved problems. ${ }^{34-38}$ When asked about barriers to better health care, insurance companies were frequently identified. One respondent said, "Insurance companies. That's the main barrier I see." Another said, "The insurance system is messing the whole system up." Yet another said, "As soon as insurance gets its fingers into the pie, then they start mandating what can be done and what can't be done. So that's one of the reasons why a lot of therapists don't want insurance to cover [CAM]. They don't want that meddling."

One respondent said, "I would like to see less priva-

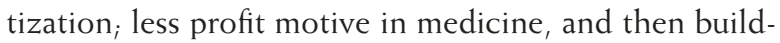
ing a more holistic approach to it, where chiropractors and general practitioners and family practitioners could allow for more prevention-more preventive medicine." Another asserted that "A collaboration between conventional practitioners and alternative practitioners ... could be really wonderful." Diversity in options was stressed, so that, "optimal health care is for people to be able to choose whichever modality they want to use." According to our informants, a system integrating CAM and conventional could better serve patient's varying health care needs over the course of a lifetime. In their vision, prevention and health maintenance would be prioritized. As one CAM practitioner said, "When you begin to integrate various powerful systems, you have a blockbuster!"

We asked our informants to identify barriers between conventional and complementary medicine and to think about possible solutions. Overwhelmingly, they noted attitudes and belief systems as more important than economic or scientific considerations. Prejudice, they said, results from lack of communication and lack of understanding, and is the major barrier to integration. As one respondent put it, "There's still a lot of fear and suspicion and prejudice about [CAM]. 'Are alternative practitioners legitimate,' you know?" Another described language and terminology as a barrier: "I think the biggest barrier is belief and ... vocabulary. I think that sometimes the words that people use or the way that a person presents himself, if it's not the vocabulary that you're used to, you have to do a lot of translation in your own mind and figure out ... you know, is this person really saying something that makes sense or not." Referrals to conventional practitioners were portrayed as one-sided, with the CAM practitioner sending patients to a conventional provider, but not receiving referrals in return. Fear of negative consequences for practicing CAM was evident in several interviews. One said, I mean, there's a whole history of the AMA being downright mean or just anti-alternative medicine ... and people get sued. People lose their livelihoods for treading in the world of mainstream medicine."

In general, CAM practitioners had kind and respectful words for conventional medicine. Although criticisms of - and challenges for-conventional medicine were common, not a single respondent suggested that CAM should replace conventional medicine. Instead, there was consensus on the proposition that CAM and conventional should work together to serve patients better. As one put it, "I don't like that word, 'alternative' because that word tends to set up an 'us and them' configuration ... 'Complementary' is a lot better word." Our respondents saw one of conventional medicine's strengths in its ability to respond rapidly and forcefully to emergent health conditions. CAM was described as having a "slower and gentler" approach, one more in tune with a deliberate and gradual means of redressing illness and attaining health.

In sum, the CAM practitioners we interviewed 
portrayed themselves as educators, coaches, and guides as well as healers. They described themselves as committed to a holistic, empowering, person-centered approach to health. They identified strengths and weaknesses of conventional medicine, and argued for an accessible, integrated, legitimate health care system.

\section{DISCUSSION}

Historically, Americans have followed many different paths in their search for health. In the 1800s, various schools of physicians followed teachings from chiropractic, eclectic medicine, faith healing, homeopathy, hydrotherapy, naturopathy, Native American medicine, osteopathy, Thomsonianism, and others. ${ }^{39}$ Conventional allopathic medicine, espousing the so-called scientific method, became clearly dominant only after the 1910 Flexner report ${ }^{40}$ when states began to restrict or condemn training and licensing of unconventional forms of practice. ${ }^{41}$ Eclectic, homeopathic, and naturopathic medical schools were closed, and several proponents were fined or jailed. Medicine in the United States moved rapidly in the direction of conformity, where it has remained for several decades.

Recently there has been a renewed growth in the number and diversity of therapeutic methods available to Americans. ${ }^{42}$ Most of these are now broadly classified as complementary, alternative, or integrative. ${ }^{1,43}$ The resurgence of unconventional therapies may in part be both a reaction to the standardized dominance of conventional medicine, and an expression of America's individualistic, consumer-oriented culture. In this regard, our work supports the findings of Astin, who in 1998 reported that people interested in environmentalism, feminism, and spiritual development were twice as likely to use CAM therapies than were their more conventional counterparts. ${ }^{32}$ The ascendance of CAM, however, may also be partly due to the collective desire for a kinder and gentler medicine, one that is more caring, patient-centered ${ }_{1}^{44-46}$ empowering, ${ }^{47,48}$ and holistic. ${ }^{49,50} \mathrm{Within}$ conventional medicine, these trends were apparent decades ago, with the publication of Engel's biopsychosocial model ${ }^{51}$ and with the rapid rise of family and community medicine. ${ }^{52-54}$ The resurgence of CAM may be another manifestation of this ongoing paradigm shift. ${ }^{55}$

Our interviews with 32 practitioners provided us with important insights into the nature of CAM, the attributes that distinguish it from conventional medicine, and the barriers to integration. Most of our respondents voiced positive regard toward conventional medicine, expressing optimism that CAM and conventional health care could eventually work together to serve better those with health care needs.
As researchers and clinicians, this optimism makes a good deal of sense to us. Improved health outcomes, increased patient satisfaction, and perhaps public health may stand to gain from such efforts. The barriers to integration are substantial, however, and the benefits are unproved. Implementing and sustaining a health care system that is holistic, empowering, accessible, and legitimate, as well as efficacious, may prove a challenging task indeed.

Our study provides one window through which to approach — and appreciate-complementary and alternative medicine. Our results support the notion that practitioners of CAM are kind, well-intentioned people who have taken it upon themselves to learn therapeutic methods aimed at improving the health of others. In closing, we would like to leave the last words to one of our respondents, who used the metaphor of a tree to describe her vision of integrated health care: "Just seeing ourselves as leaves on a tree- $a$ tree of healing-and each of us is a leaf on that tree, each modality is, you know, a leaf on that tree. If there was only one leaf on a tree, the tree would not be able to offer much as far as air quality or beauty.... I guess I would like us be able to see us move toward a place of greater acceptance of one another, that we all have a branch on this tree and that we're all a vital part of the health of the community."

To read or post commentaries in response to this article, see it online at http://www.annfammed.org/cgi/content/full/2/3/253.

Keywords: Alternative medicine; complementary medicine; integrated health care; in-depth interviews; qualitative methods

Submitted September 24, 2003; submitted, revised, May 9, 2003; accepted July 5, 2003

Funding support: Bruce Barrett is partially supported by a Patient-Oriented Career Development Grant (K23 AT00051-01) from the National Center for Complementary and Alternative Medicine at the National Institutes of Health.

Acknowledgments: The authors would like to acknowledge the practitioners of complementary and alternative medicine who contributed their time and ideas towards this endeavor. They would also like to acknowledge the Department of Family Medicine at the University of Wisconsin-Madison for providing the institutional home for this project.

\section{References}

1. Jonas WWB, Levin JS. Essentials of Complementary and Alternative Medicine. Baltimore, Md: Lippincott Williams \& Wilkins, 1999.

2. Eisenberg DM, Kessler RC, Foster C, Norlock FE, Calkins DR, Delbanco TL. Unconventional medicine in the United States: prevalence, costs, and patterns of use. N Engl J Med. 1993;328:246-252.

3. Ernst E, Resch K-L, Mills S, et al. Complementary medicine: a definition. Br J Gen Pract. 1995;45:506.

4. Ernst E, Eisenberg DM, Pittler MH, et al. The Desktop Guide to Complementary and Alternative Medicine. Edinburgh: Mosby; 2001. 
5. Eisenberg DM, Davis RB, Ettner SL, et al. Trends in alternative medicine use in the United States, 1990-1997. JAMA. 1998;280:15691575.

6. Berman BM. Complementary medicine and medical education. BMJ 2001;322:121-122

7. Consumers Union. The mainstreaming of alternative medicine. Consum Rep. 2000; 17:17-25.

8. Ernst E. Prevalence of use of complementary/alternative medicine: a systematic review. Bull World Health Organ. 2000;78:252-257.

9. Palinkas LA, Kabongo ML. The use of complementary and alternative medicine by primary care patients. A SURF*NET study. J Fam Pract. 2000;49:1121-1130.

10. Shumay DM, Maskarinec G, Kakai H, Gotay CC. Why some cancer patients choose complementary and alternative medicine instead of conventional treatment. J Fam Pract. 2001;50:1067.

11. Adler SR, Fosket JR. Disclosing complementary and alternative medicine use in the medical encounter: a qualitative study in women with breast cancer. J Fam Pract. 1999;48:453-458.

12. Cassidy CM. Social science theory and methods in the study of alternative and complementary medicine. J Alt Comp Med. 1995;1:19-40.

13. Barrett B, Marchand L, Scheder J, et al. Bridging the gap between conventional and alternative medicine: results of a qualitative study of patients and providers. J Fam Pract. 2000;49:234-239.

14. Kelner M, Wellman B. Health care and consumer choice: medical and alternative therapies. Soc Sci Med. 1997;45:203-12.

15. Pawluch D, Cain R, Gillett J. Lay constructions of HIV and complementary therapy use. Soc Sci Med. 2000;51:251-264.

16. Britten N. Qualitative interviews in medical research. BMJ. 1995;311:251-253

17. Crabtree BF, Miller WF. Doing Qualitative Research. Thousand Oaks, Calif: Sage Publications; 1992.

18. Crabtree BF, Miller WL. Qualitative approach to primary care research: the long interview. Fam Med. 1991;23:145-151.

19. Denzin NK, Lincoln YS. Handbook of Qualitative Research. Thousand Oaks, Calif: Sage Publications; 1993.

20. Devers KJ, Sofaer S, Rundall TG. Qualitative methods in health services research. Health Serv Res. 1998;34:1083-1263.

21. Kuzel AJ. Naturalistic inquiry: an appropriate model for family medicine. Fam Med. 1986;18:369-374.

22. Mays N, Pope C. Rigour and qualitative research. BMJ. 1995;311: 109-112.

23. McCracken G. The Long Interview. Thousand Oaks, Calif: Sage Publications; 1988

24. Rakel D. Intetrative Medicine. Philadelphia, London, New York: Elsevier Science, Saunders; 2003.

25. Miller WL, Crabtree BF, Yanoshik MK. Expanding the boundaries of family medicine research. Fam Med. 1991;23:425-6.

26. Malterud K. Qualitative research: standards, challenges, and guidelines. Lancet. 2001;358:483-488.

27. Miller WL, Crabtree BF. Qualitative analysis: how to begin making sense. Fam Pract Res J. 1994;14:289-96.

28. Miller WL, Yanoshik K, Crabtree BF, Reymond WK. Patients, family physicians, and pain: visions from interview narratives. Clin Res Meth. 1994;26:179-184

29. NUD*IST Vivo (N-Vivo). 1999. Melbourne, Qualitative Solutions and Research Pty. Ltd. Ref Type: Computer Program

30. Ray PH. The Integral Culture Survey: A Study Of The Emergence Of Transformational Values In America. Sausalito, Calif: Institute of Noetic Sciences; 1996:96-A:1-161.
31. Ray PH, Anderson SR. The Cultural Creatives: How 50 Million People Are Changing the World. New York, NY: Harmony Books; 2000.

32. Astin JA. Why patients use alternative medicine: results of a national study. JAMA. 1998;279:1548-1553.

33. Himmelstein DU, Woolhandler S. A national health program for the United States. N Engl J Med. 1989;320:102-108.

34. Donelan K, Blendon RJ, Benson J, Leitman R, Taylor H. All payer, single payer, managed care, no payer: patients' perspectives in three nations. Health Aff (Millwood). 1996;15:254-265.

35. Ferrer RL. Within the system of no-system. JAMA. 2001;286:25132514

36. Himmelstein DU, Woolhandler S, Hellander I. Bleeding the Patient: The Consequences of Corporate Health Care. Philadelphia, PA: Common Courage Press; 2001.

37. Institute of Medicine, National Academy of Sciences, National Academy of Engineering, and National Research Council. U.S. health care delivery system needs major overhaul to improve quality and safety. March 1, 2001. NEWS [online newsletter]. Available at http://www4. nationalacademies.org/news.nsf/isbn/0309072808?OpenDocument.

38. Starfield B. Is US health really the best in the world? JAMA. 2000;284:483-485

39. Whorton JC. The history of complementary and alternative medicine. In Jonas W, Levin JS, eds. Essentials of Complementary and Alternative Medicine. Baltimore, Md: Lippincott, Williams \& Wilkins; 1999: 6-30.

40. Berliner HS. A larger perspective on the Flexner report. Int J Health Serv. 1975;5:573-592

41. Starr P. The Social Transformation of American Medicine. New York, NY: Basic Books; 1982

42. Kaptchuk TJ, Eisenberg DM. Varieties of healing. 1: medical pluralism in the United States. Ann Int Med. 2001;135:189-195.

43. Kaptchuk TJ, Eisenberg DM. Varieties of healing. 2: a taxonomy of unconventional healing practices. Ann Int Med. 2001;135:196-204

44. Kinnersley P, Stott N, Peters TJ, Harvey I. The patient-centredness of consultations and outcome in primary care. Br J Gen Pract. 1999;49: 711-716.

45. Rao JK, Weinberger M, Kroenke K. Visit-specific expectations and patient-centered outcomes. Arch Fam Med. 2000;9:1148-1155.

46. Stewart MA, Brown JB, Donner A, et al. The impact of patient-centered care on outcomes. J Fam Pract. 2000;49:796-804.

47. Brown ER. Community action for health promotion: A strategy to empower individuals and communities. Int J Health Serv. 1991;21 441-456.

48. Mansell D, Poses RM, Kazis L, Duefield CA. Clinical factors that influence patients' desire for participation in decisions about illness. Arch Intern Med. 2000;160:2991-2996.

49. Pelletier K. Holistic Medicine: From Stress to Optimum Health. New York, NY: Dell Publishing; 1979.

50. Woods S. A theory of holism for nursing. Med Health Care Philos. 1998;1:255-261.

51. Engel GL. The need for a new medical model: a challenge for biomedicine. Science. 1977;196:129-136.

52. Stephens GG. The intellectual basis of family practice. J Fam Pract. $1975: 2: 423-428$

53. Miller WL. Models of health, illness, and health care. In: Family Medicine: Principles and Practice. New York, Berlin, London: SpringerVerlag; 1988.

54. Frey JJ. Building our sense of place. Fam Med. 1998;30:401-403.

55. Kuhn T. The Structure of Scientific Revolutions. Chicago, III: University of Chicago Press; 1962. 